\title{
Overexpression of PAX5 in oral carcinogenesis
}

\author{
SUFI NORHANY ${ }^{1 *}$, YUKINAO KOUZU ${ }^{2 *}$, KATSUHIRO UZAWA $^{2,3}$, MASAYO HAYAMA $^{1}$, \\ MORIHIRO HIGO $^{2}$, HIROFUMI KOIKE ${ }^{2}$, ATSUSHI KASAMATU ${ }^{2}$ and HIDEKI TANZAWA ${ }^{2-4}$ \\ ${ }^{1}$ School of Medicine; ${ }^{2}$ Department of Clinical Molecular Biology, Graduate School of Medicine; \\ ${ }^{3}$ Division of Dentistry and Oral-Maxillofacial Surgery; ${ }^{4}$ Center of Excellence (COE) Program in the 21st Century, \\ Graduate School of Medicine, Chiba University, 1-8-1 Inohana, Chuo-ku, Chiba 260-8670, Japan
}

Received June 22, 2006; Accepted August 2, 2006

\begin{abstract}
The oncogenic transcription factor PAX5 is an important developmental regulator and is implicated in the pathogenesis of several malignancies. The PAX5 gene is involved in medulloblastoma, non-Hodgkin's lymphoma, transitional cell carcinoma of the bladder, neuroblastoma, breast cancer and SCC. In the current study, to determine the potential involvement of PAX5 in oral squamous-cell carcinoma (OSCC) and leukoplakias, we evaluated the status of PAX5 mRNA and protein expression in OSCC cell lines, human primary OSCCs, and leukoplakias by real-time quantitative reverse transcriptase-polymerase chain reaction, Western blot analysis, and immunohistochemistry. A significant increase in PAX5 expression was observed in all OSCC-derived cell lines examined compared to human normal oral keratinocytes (HNOKs). In immunohistochemistry, $78 \%$ of tumors and $42 \%$ of leukoplakias examined were positive for PAX5, while no immunoreaction was observed in corresponding normal tissues. The results suggest that PAX5 plays an important role during oral carcinogenesis, especially in the early stage, and that the gene may have potential as a biomarker and therapeutic target for OSCC.
\end{abstract}

\section{Introduction}

Oral squamous cell carcinoma (OSCC) is the most common cancer of the head and neck and accounts for over 300,000 new cancer cases worldwide annually (1). With the currently available clinical assessment and treatment methods, patients are often diagnosed at late stages of the disease and the survival rate has not improved substantially. This highlights the need for continued effort to discover suitable biomarkers for early disease diagnosis and to understand the disease pathogenesis

Correspondence to: Professor Hideki Tanzawa, Chiba University, 1-8-1 Inohana, Chuo-ku, Chiba 260-8670, Japan

E-mail: tanzawap@faculty.chiba-u.jp

*Contributed equally

Key words: PAX5, oral squamous-cell carcinoma, real-time quantitative RT-PCR, Western blot, immunohistochemistry as a first step toward improving treatment. Elucidation of the genetic changes leading to the development of OSCCs will probably result in improved molecular assays for the early diagnosis of, therapy for, and improved prognosis of this cancer. The availability of biomarkers of malignancy would also be a key factor for monitoring cancer recurrence and evaluating the efficacy of novel treatment or chemopreventive agents.

PAX5 is a member of the PAX gene family of developmentally regulated transcription factors that play a fundamental role in organogenesis (2). All PAX transcription factors share a DNA binding domain, the paired box. Their importance in development has been underscored by several loss-of-function mutations that cause lack of a specific structure or organ in which the corresponding $P A X$ gene is normally expressed. Typically, PAX protein expression is down-regulated in the adult organism. PAX5 is expressed during all stages of B-cell development, except in plasma cells (3). In addition to the normal physiologic function during development, PAX transcription factors play an important role in tumorigenesis (4). First, a number of $P A X$ genes are located at recurring, tumorspecific chromosomal translocations, suggesting that $P A X$ genes have an oncogenic capacity when inappropriately expressed (5). Second, several $P A X$ genes are re-expressed in malignant neoplasms, usually in tumors derived from tissue in which the respective $P A X$ gene is expressed during development (5). For example, deregulated expression of PAX5 has been described in medulloblastoma and lymphomas $(6,7)$ and of PAX3 in melanoma (8). It is speculated that the re-expressed $P A X$ genes promote tumor development and progression by increasing proliferation and motility, while inhibiting apoptosis (4). However, the status of PAX5 in OSCC remains unclear.

The major purpose of this study was to examine the expression of PAX5 mRNA and protein in OSCC-derived cell lines, human primary OSCCs, and leukoplakias.

\section{Materials and methods}

Tissue specimens and cell lines. Tumors or leukoplakias, with patient-matched normal epithelium when available, were obtained at the time of surgical resection at Chiba University Hospital after the patient's informed consent had been obtained under a protocol approved by the institutional review board 
of Chiba University, Japan. Resected tissues were immediately frozen and stored in liquid nitrogen. Histopathological diagnosis of each neoplastic tissue was performed, according to the World Health Organization criteria, by the Department of Pathology, Chiba University Hospital. Clinicopathologic staging was determined by the TNM classification of the International Union against Cancer. All patients had histologically confirmed SCC or leukoplakia, and tumor samples were checked to ensure that tumor tissue was present in $>80 \%$ of the specimens.

The OSCC-derived cell lines used in this study were HSC-2, HSC-3, HSC-4, Ca9-22 (Human Science Research Resources Bank, Osaka, Japan), and Sa3 (provided by Dr Shigeyuki Fujita at Wakayama Medical University, Wakayama, Japan). All OSCC-derived cell lines were grown in Dulbecco's modified Eagle medium/F-12 HAM (SigmaAldrich Co., St. Louis, MO, USA) supplemented with $10 \%$ fetal bovine serum (Sigma) and 50 units $/ \mathrm{ml}$ penicillin and streptomycin (Sigma). Healthy oral gingival specimens were collected from 22- to 35-year-old patients at Chiba University Hospital with the approval of the institutional review board of Chiba University. Five independent human normal oral keratinocytes (HNOKs) were primary cultured and maintained in defined keratinocyte-SFM (Gibco BRL, Gaithusberg, Germany) (9).

mRNA and protein extraction. Total RNA was extracted using Trizol Reagent (Invitrogen Life Technologies, Carlsbad, CA, USA), according to the manufacturer's instructions. Each specimen of extracted RNA was stored separately at $-80^{\circ} \mathrm{C}$ until use. Protein was extracted from the cells when they reached $80-90 \%$ confluence; they were washed twice with phosphate-buffered saline (PBS), scraped into a tube, and centrifuged briefly. The cell pellets were incubated for $30 \mathrm{~min}$ in a lysis buffer containing $7 \mathrm{M}$ urea, $2 \mathrm{M}$ thiourea, $4 \% \mathrm{w} / \mathrm{v}$ CHAPS, and $10 \mathrm{mM}$ Tris $\mathrm{pH} 8.0$, and lysed by sonication ( $3 \times 10 \mathrm{sec}$ pulses on ice). The sample was centrifuged at $13,000 \mathrm{rpm}$ for $20 \mathrm{~min}$. The supernatant containing the cell proteins then was recovered, and the protein concentration was measured with a protein assay kit (Bio-Rad Laboratories, Hercules, CA, USA) and adjusted to $1 \mathrm{mg} / \mathrm{ml}$ with a lysis buffer. The $\mathrm{pH}$ of the protein sample was adjusted to 8.5 with $30 \mathrm{mM}$ Tris- $\mathrm{HCl}$.

mRNA expression analysis. We examined the expression levels of PAX5 mRNA in OSCC-derived cell lines (HSC-2, HSC-3, HSC-4, Ca9-22, and Sa3) and HNOKs. Real-time quantitative reverse transcriptase-polymerase chain reaction (qRT-PCR) was performed with a single method using a LightCycler FastStart DNA Master SYBR Green 1 kit (Roche Diagnostics GmbH, Mannheim, Germany), according to the procedure provided by the manufacturer. The primer sequences used to analyze PAX5 mRNA expression were forward 5'CCTCTCTTCCTCCAGGGACT -3' and reverse 5'- GCCCA CAGAAAAGCAAGAAG -3'. The sequence of specific primers was checked before use to avoid amplification of genomic DNA or pseudogenes using the Primer3 program (available at http://www-genome.wi.mit.edu/cgi-bin/primer/ primer3_www.cgi). The PCR reactions using LightCycler apparatus were carried out in a final volume of $20 \mu 1$ of a reaction mixture consisting of $2 \mu 1$ of FirstStart DNA Master SYBR Green I mix (Roche), $3 \mathrm{mM} \mathrm{MgCl}_{2}$, and $0.2 \mu 1$ of the primers, according to the manufacturer's instructions. The reaction mixture then was loaded into glass capillary tubes and subjected to an initial denaturation at $95^{\circ} \mathrm{C}$ for $10 \mathrm{~min}$, followed by 45 rounds of amplification at $95^{\circ} \mathrm{C}(10 \mathrm{sec})$ for denaturation, $63^{\circ} \mathrm{C}(10 \mathrm{sec})$ for annealing, and $72^{\circ} \mathrm{C}$ for extension, with a temperature slope of $20^{\circ} \mathrm{C} / \mathrm{sec}$, performed in the LightCycler. The transcript amount for the PAX5 gene was estimated from the respective standard curves and normalized to the glyceraldehyde-3-phosphate dehydrogenase (GAPDH) (forward 5'-CATCTCTGCCCCCTCTGC TGA-3' and reverse 5'-GGATGACCTTGCCCACAGCCT-3') transcript amount determined in corresponding samples. Data are expressed as the means \pm SD of 2 independent experiments with triplicate samples.

Western blot analysis. Protein extracts were electrophoresed on $11 \%$ sodium dodecyl sulfate-polyacrylamide gel electrophoresis gels, transferred to PVDF membranes (Bio-Rad), and blocked for $1 \mathrm{~h}$ at room temperature in 5\% skim milk. The immunoblot PVDF membranes were washed 5 times with $0.1 \%$ Tween-20 in TBS (TBS-T), and $2 \mu \mathrm{g} / \mathrm{ml}$ affinity-purified goat anti-human PAX5 polyclonal antibody (Santa Cruz Biotechnology, Santa Cruz, CA) was added directly to the TBS-T solution for $2 \mathrm{~h}$ at room temperature. PVDF membranes were washed again and incubated with 1:1000 of horseradish peroxidase-conjugated antigoat IgG Envision+ (Dako Japan Inc., Kyoto, Japan) as a secondary antibody for $20 \mathrm{~min}$ at room temperature. Finally, the membranes were incubated with ECL+-horseradish peroxidase substrate solution included in the ECL+ kit (Amersham Biosciences UK Ltd., UK), and immunoblotting was visualized by exposing the membrane to Hyperfilm (Amersham).

Immunohistochemistry. We performed immunohistochemical staining on $4-\mu \mathrm{m}$ sections of paraffin-embedded specimens with the use of goat anti-human PAX5 polyclonal antibody (Santa Cruz). Briefly, after deparaffinization and hydration, the slides were treated with endogenous peroxidase in $0.3 \%$ $\mathrm{H}_{2} \mathrm{O}_{2}$ for $30 \mathrm{~min}$, after which the sections were blocked for $2 \mathrm{~h}$ at room temperature with $1.5 \%$ blocking serum (Santa Cruz) in PBS before reacting with anti-PAX5 antibody (1:1000 dilution) at room temperature in a moist chamber overnight. Upon incubation with the primary antibody, the specimens were washed 3 times in PBS and treated with Envision reagent followed by color development in 3,3'-diaminobenzidine tetrahydrochloride (Dako). The slides were lightly counterstained with hematoxylin, dehydrated with ethanol, cleaned with xylene, and mounted. As a negative control, duplicate sections were immunostained without exposure to primary antibodies. To quantitate the status of PAX5 protein expression, the mean percentage of positive tumor cells was determined in at least five random fields at $\times 400$ magnification in each field. The intensity of the PAX5 immunoreaction was scored as follows: $1+$, weak; $2+$, moderate; and $3+$, intense. The percentage of positive tumor cells and the staining intensity then were multiplied to produce a PAX5-immunohistochemical staining score. Cases with a PAX5 score $>76.9$ (the highest score for normal tissue) were defined as positive. These 
Table I. Correlation between PAX5 expression and clinical classification in OSCCs.

\begin{tabular}{|c|c|c|c|c|}
\hline \multirow[b]{2}{*}{ Clinical classification } & \multirow[b]{2}{*}{ Total } & \multicolumn{2}{|c|}{$\begin{array}{l}\text { Results of immunostaining } \\
\text { No. patients }(\%)\end{array}$} & \multirow[b]{2}{*}{ P-value ${ }^{a}$} \\
\hline & & PAX5 (-) & $\operatorname{PAX} 5(+)$ & \\
\hline \multicolumn{5}{|l|}{ Age at surgery (years) } \\
\hline$<60$ & 19 & $4(21)$ & $15(79)$ & \multirow{3}{*}{0.997037} \\
\hline$\geq 60,<70$ & 12 & $2(17)$ & $10(83)$ & \\
\hline$\geq 70$ & 19 & $5(26)$ & $14(74)$ & \\
\hline \multicolumn{5}{|l|}{ Gender } \\
\hline Male & 29 & $5(17)$ & $24(83)$ & \multirow[t]{2}{*}{0.677405} \\
\hline Female & 21 & $6(29)$ & $15(71)$ & \\
\hline \multicolumn{5}{|l|}{ T-primary tumor } \\
\hline $\mathrm{T} 1$ & 5 & $1(20)$ & $4(80)$ & \multirow{4}{*}{0.832745} \\
\hline $\mathrm{T} 2$ & 27 & $7(26)$ & $20(74)$ & \\
\hline T3 & 8 & $0(0)$ & $8(100)$ & \\
\hline $\mathrm{T} 4$ & 10 & $3(30)$ & $7(70)$ & \\
\hline \multicolumn{5}{|l|}{ N-regional lymph node } \\
\hline $\mathrm{N}(-)$ & 25 & $7(28)$ & $18(72)$ & \multirow[t]{2}{*}{0.631773} \\
\hline $\mathrm{N}(+)$ & 25 & $4(16)$ & $21(84)$ & \\
\hline \multicolumn{5}{|l|}{ Stage } \\
\hline I & 5 & $1(20)$ & $4(80)$ & \multirow{4}{*}{0.826432} \\
\hline II & 14 & $5(36)$ & $9(64)$ & \\
\hline III & 6 & $0(0)$ & $6(100)$ & \\
\hline IV & 25 & $5(20)$ & $20(80)$ & \\
\hline \multicolumn{5}{|l|}{ Histopathological type } \\
\hline Well differentiated & 33 & $8(24)$ & $25(76)$ & \multirow{3}{*}{1.000000} \\
\hline Moderately differentiated & 10 & $2(20)$ & $8(80)$ & \\
\hline Poorly differentiated & 7 & $1(14)$ & $6(86)$ & \\
\hline \multicolumn{5}{|l|}{ Tumor site } \\
\hline Gingiva & 17 & $4(24)$ & $13(76)$ & \multirow{5}{*}{0.970242} \\
\hline Tongue & 25 & $5(20)$ & $20(80)$ & \\
\hline Buccal mucosa & 3 & $1(33)$ & $2(67)$ & \\
\hline Oral floor & 3 & $0(0)$ & $3(100)$ & \\
\hline Oropharynx & 2 & $1(50)$ & $1(50)$ & \\
\hline
\end{tabular}

${ }^{\mathrm{a}} \mathrm{P}<0.05$ is considered significant.

judgments were made by two independent pathologists, neither of whom had knowledge or information about the patients' clinical status. Statistical significance was evaluated by the Fisher's exact test or Mann-Whitney's U test. $\mathrm{P}<0.05$ was considered significant.

\section{Results}

Analyses of mRNA and protein expression of PAX5 in cell lines. qRT-PCR analysis data showed that expression of PAX5 mRNA was significantly up-regulated in all five OSCCderived cell lines compared to the HNOKs (Fig. 1A). The
PAX5 mRNA expression levels in the HNOKs and OSCCderived cell lines ranged from 4 to 6 (mean, 4.67) and 17 to 57 (mean, 32.6), respectively.

We also evaluated the status of PAX5 protein expression in five OSCC-derived cell lines and HNOKs by Western blot analysis. Fig. 1B shows representative results. The band size detected was $50 \mathrm{kDa}$, as reported by Baumann Kubetzko (5), and a significant increase in PAX5 expression was observed in all OSCC-derived cell lines compared with the HNOKs. mRNA and protein analyses indicated that both transcription and translation products of this molecule were highly expressed in OSCC-derived cell lines. 
A

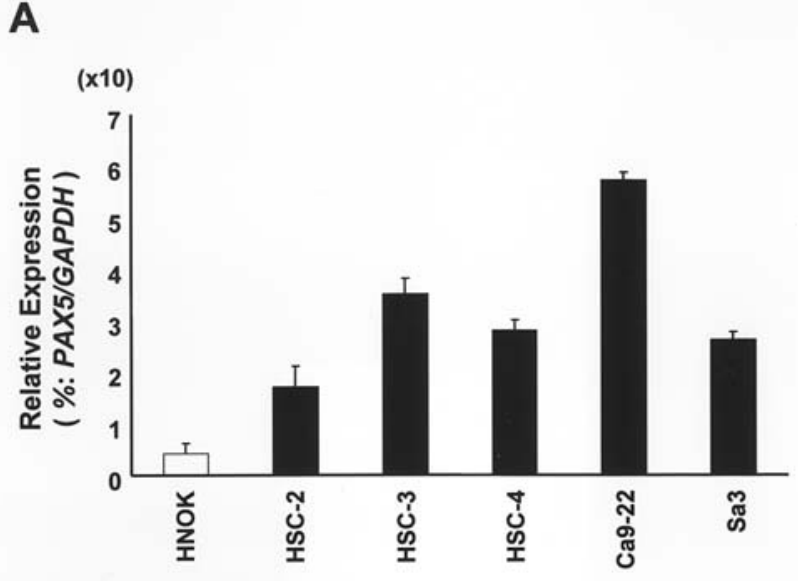

B

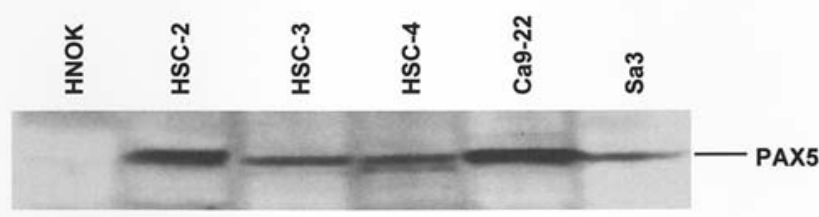

Figure 1. PAX5 mRNA and protein expression in OSCC-derived cell lines. (A) Quantification of mRNA levels in OSCC-derived cell lines by qRTPCR analysis. Significant up-regulation of the PAX5 gene is seen in all OSCC-derived cell lines compared to PAX5 mRNA expression in HNOKs. Data are expressed as means \pm SD. (B) Western blot analysis of PAX5 protein in OSCC-derived cell lines and HNOKs. HNOK extracts do not significantly express PAX5 protein. OSCC-derived-cell line extracts exhibit PAX5 protein expression.

Immunohistochemical analysis. Fifty patients with OSCC were identified for whom there was adequate histologic material available for immunohistochemical analysis. The correlation between the clinicopathological characteristics of the patients with OSCC and the status of PAX5 expression is summarized in Table I. Normal oral mucosa specimens had no or significant down-regulation of PAX5 expression and were considered PAX5-negative. Among the tumors examined, 39 of 50 cases (78\%) had a PAX5 immunoreaction in the nucleus of the tumor cells (Table I). However, there was no significant difference between PAX5 expression and the clinicopathological features (Table I). Of 26 leukoplakias (42\%) 11 were considered PAX5-positive. Representative results for PAX5 protein expression in normal oral tissues, leukoplakias, and primary OSCCs are shown in Fig. 2. The PAX5 immunohistochemistry scores for normal tissues, leukoplakias, and OSCCs ranged from 4.8 to 76.9 (mean, 40.3), from 21.3 to 204.4 (mean, 82.9), and 37.3 to 240 (mean, 115.2), respectively. The PAX5 expression levels in both primary OSCCs and leukoplakias were significantly higher than that in normal oral tissues (Mann-Whitney $\mathrm{U}$ test, $\mathrm{P}<0.0001$; Fig. 3). We also found significant differences in PAX5 immunohistochemistry scores between OSCCs and leukoplakias (Mann-Whitney U test, $\mathrm{P}<0.05$, Fig. 3).

\section{Discussion}

The PAX family to which the PAX5 gene belongs has nine members, each of which shares a common motif, called the

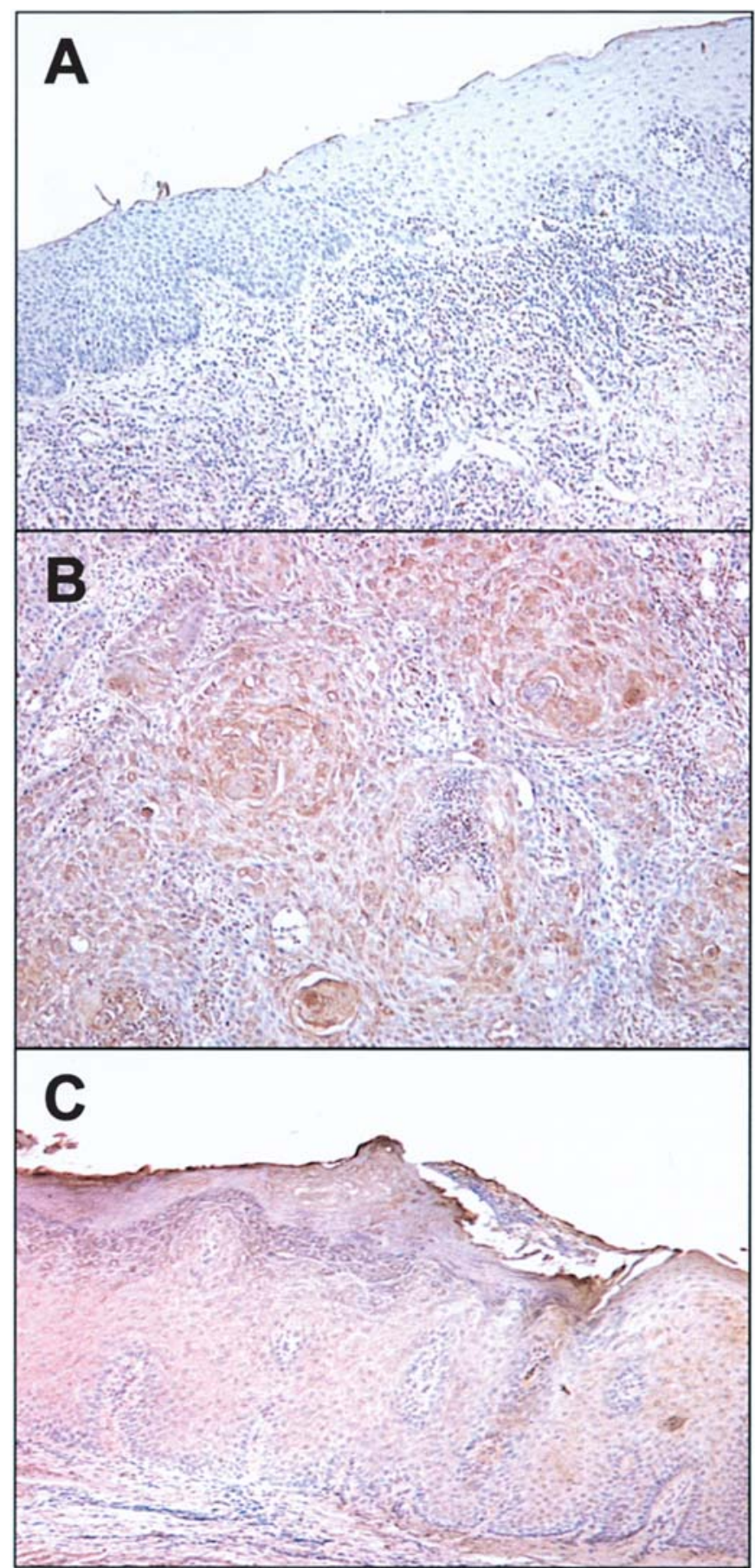

Figure 2. Immunohistochemical staining of PAX5 in normal, pre-malignan (leukoplakia), and malignant (OSCC) tissue. (A) Normal oral tissue has no PAX5 protein expression. Original magnification, x200. (B) PAX5-positive case of OSCC. Strong positive immunoreaction for PAX5 is detected in the nucleus of the tumor cell. Original magnification, x200. (C) PAX5-positive case of leukoplakia. Strong positive immunoreaction for PAX5 is detected on the epithelial cell nucleus. Original magnification, $\mathrm{x} 200$.

paired box $(10,11) . P A X$ genes are in the nucleus, encode nuclear transcription factors that are important regulators in embryonic development, and bind to DNA in vitro (12). Since the $P A X$ genes have an important role in embryonic development, their expression has been demonstrated in a number of human cancers (13). The PAX5 gene is involved in medulloblastoma (13), non-Hodgkin's lymphoma (14), transitional cell carcinoma of the bladder (15), neuroblastoma (5), breast 


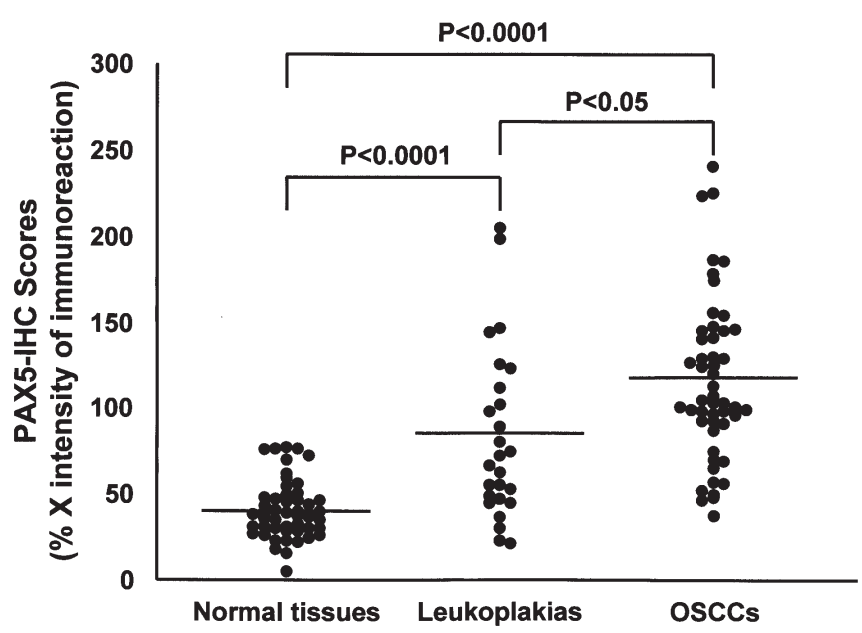

Figure 3. Status of PAX5 protein expression in normal tissues $(n=50)$, leukoplakias $(n=26)$, and primary OSCCs $(n=50)$. The PAX5 immunohistochemistry $($ IHC) scores were calculated as: PAX5-IHC score $=($ the percentage of positive tumor cells) $x$ the staining intensity. PAX5 protein expression in leukoplakias and OSCCs is significantly higher than in normal oral tissues $(\mathrm{P}<0.0001$, Mann-Whitney $\mathrm{U}$ test $)$; a significant difference in protein expression is observed between leukoplakias and OSCCs $(\mathrm{P}<0.05$, Mann-Whitney U test).

cancer, and SCC (16). However, the status of PAX5 in OSCC remains unclear.

To clarify the relative status of PAX5 in OSCC, we investigated the mRNA/protein expression in a series of OSCC-derived cell lines, leukoplakias, and human primary OSCCs using qRT-PCR, Western blot analysis, and immunohistochemistry. Significant increases in PAX5 mRNA and protein expression levels were observed in the OSCC-derived cell lines examined compared with the HNOKs. We also detected a comparatively strong tumor cell-localized nucleus PAX5 immunoreaction in primary OSCCs. In addition, PAX5 expression was seen in $42 \%$ of the leukoplakias evaluated. By evaluating the PAX5 immunohistochemistry scores using the Mann-Whitney U test, significant PAX5 up-regulation was evident in the primary OSCCs and leukoplakias $(\mathrm{P}<0.0001)$ compared with normal tissues. Moreover, we found a significant difference in PAX5 expression between OSCCs and leukoplakias $(\mathrm{P}<0.05)$. PAX5 is important in the pathogenesis of malignant astrocytoma and is most highly overexpressed in the more aggressive form of the disease, glioblastoma multiforme, suggesting a possible role in progression (17). Thus, we postulated that the status of PAX5 expression may be an important discriminator for OSCC progression. However, the current results were not as good as expected, because no relation was found between the degree of PAX5 expression and the grade or stage of OSCC examined in this study. Therefore, we suggest that PAX5 protein accumulation may be an early event during oral carcinogenesis. Future studies on a large series of patients should provide more accurate information about the involvement of PAX5 expression in the development of oral carcinogenesis.

In carcinogenesis, p53 is a key gene responsible for cell cycle control and preservation of genomic integrity (18). There is an interesting inverse relationship between PAX5 expression and expression of p53 protein in astrocytomas
(19). Subsequent in vitro experiments showed the ability of PAX5 protein to bind to a sequence within the five regulatory regions of the human $p 53$ gene and repress its activity (19). However, we did not observe a negative dependence between the quantity of PAX5 expression and expression of p53 protein. In this context, we emphasize that even the evidence reported by Stuart et al is ambiguous (19). The absence of p53 immunohistochemical positivity cannot differentiate physiologic conditions related to the presence of wild-type p53 and conditions with repressed p53 activity. Recent studies have reported that from a prognostic viewpoint, high expression of both PAX5 and p53 seems to be connected to higher recurrence and progression rates in superficial bladder carcinoma (20). PAX5 expression may be linked closely to the p53-related pathway in the development of OSCC.

In conclusion, the current study identified aberrant PAX5 expression in leukoplakias and OSCCs, suggesting that PAX5 may be correlated with oral carcinogenesis. In addition, leukoplakia is a premalignant lesion, and the epithelium adjacent to the tumor also is at high risk for malignant transformation (21). Our results imply that expression of PAX5 may be an indicator of potential malignant development in premalignant oral lesions. Therefore, PAX5 is an important gene in early development and a therapeutic target for OSCC.

\section{References}

1. Lippman SM, Sudbo J and Hong WK: Oral cancer prevention and the evolution of molecular-targeted drug development. J Clin Oncol 23: 346-356, 2005.

2. Chi N and Epstein JA: Getting your Pax straight: Pax proteins in development and disease. Trends Genet 18: 41-47, 2002.

3. Adams B, Dorfler P, Aguzzi A, Kozmik Z, Maurer-Fogy I, Urbanek P and Busslinger M: Pax-5 encodes the transcription factor BSAP and is expressed in B lymphocytes, the developing CNS and adult testis. Genes Dev 6: 1589-1607, 1992.

4. Schafer BW: Emerging roles for PAX transcription factors in cancer biology. Gen Physiol Biophys 17: 211-224, 1998.

5. Baumann Kubetzko FB, Di Paolo C, Maag C, Meier R, Schafer BW, Betts DR, Stahel RA and Himmelmann A: The PAX5 oncogene is expressed in N-type neuroblastoma cells and increases tumorigenicity of a S-type cell line. Carcinogenesis 25: 1839-1846, 2004.

6. Kozmik Z, Sure U, Ruedi D, Busslinger M and Aguzzi A: Deregulated expression of PAX5 in medulloblastoma. Proc Natl Acad Sci USA 92: 5709-5713, 1995.

7. Krenacs L, Himmelmann AW, Quintanilla-Martinez L, Fest T, Riva A, Wellmann A, Bagdi E, Kehrl JH, Jaffe ES and Raffeld M: Transcription factor B-cell-specific activator protein (BSAP) is differentially expressed in B cells and in subsets of B-cell lymphomas. Blood 92: 1308-1316, 1998.

8. Scholl FA, Kamarashev J, Murmann OV, Geertsen R, Dummer R and Schafer BW: PAX3 is expressed in human melanomas and contributes to tumor cell survival. Cancer Res 61: 823-826, 2001.

9. Koike H, Uzawa K, Nakashima D, Shimada K, Kato Y, Higo M, Kouzu Y, Endo Y, Kasamatsu A and Tanzawa H: Identification of differentially expressed proteins in oral squamous-cell carcinoma using a global proteomic approach. Int J Oncol 27: 59-67, 2005.

10. Busslinger M and Urbanek P: The role of BSAP (Pax-5) in B-cell development. Curr Opin Genet Dev 5: 595-601, 1995.

11. Tiacci E, Pileri S, Orleth A, Pacini R, Tabarrini A, Frenguelli F, Liso A, Diverio D, Lo-Coco F and Falini B: PAX5 expression in acute leukemias: higher B-lineage specificity than CD79a and selective association with $\mathrm{t}(8 ; 21)$-acute myelogenous leukemia. Cancer Res 64: 7399-7404, 2004.

12. Chalepakis G, Tremblay P and Gruss P: PAX genes, mutants and molecular function. J Cell Sci 16 (Suppl): 61-67, 1992.

13. Stuart ET and Gruss P: PAX: developmental control genes in cell growth and differentiation. Cell Growth Differ 7: 405-412, 1996. 
14. Zhang X, Lin Z and Kim I: Pax5 expression in non-Hodgkin's lymphomas and acute leukemias. J Korean Med Sci 18: 804-808, 2003.

15. Adshead JM, Ogden CW, Penny MA, Stuart ET and Kessling AM: The expression of PAX5 in human transitional cell carcinoma of the bladder: relationship with the dedifferentiation. BJU Int 83: 1039-1044, 1999.

16. Palmisano WA, Crume KP, Grimes MJ, Winters SA, Toyota M, Esteller M, Joste N, Baylin SB and Belinsky SA: Aberrant promoter methylation of the transcription factor genes PAX5 and $B$ in human cancers. Cancer Res 63: 4620-4625, 2003.

17. Stuart ET, Kioussi C, Aguzzi A and Gruss P: PAX5 expression correlates with increasing malignancy in human astrocytomas. Clin Cancer Res 1: 207-214, 1995.
18. Levine AJ: p53, the cellular gatekeeper for growth and division. Cell 88: 323-331, 1997

19. Stuart ET, Haffner R, Oren M and Gruss P: Loss of p53 functions through PAX-mediated transcriptional repression. EMBO J 14: 5638-5645, 1995.

20. Babjuk M, Soukup, V, Mares, Duskova J, Sedlácek Z, Trková M, Pecen L, Dvoracek J, Hanus T, Kocvara R, Novak J and Povysil C: The expression of PAX5, p53 immunohistochemistry and p53 mutation analysis in superficial bladder carcinoma tissue. Correlation with pathological findings and clinical outcome. Int Urol Nephrol 34: 495-501, 2002.

21. Slaughter DL, Southwick HW and Smejkal W: Field cancerization in oral stratified squamous epithelium. Cancer 6 : 963-968, 1953. 